\title{
Lack of association between Borna disease virus infection and neurological disorders among HIV-infected individuals
}

\author{
Stefano Bachmann ${ }^{1}$, Patrick Caplazi ${ }^{2}$, Marek Fischer ${ }^{1}$, Felix Ehrensperger $^{2}$ and Richard W Cone ${ }^{1}$ \\ ${ }^{1}$ Division of Infectious Diseases, Department of Internal Medicine, University Hospital, Ramistrasse 100, CH-8091 \\ Zurich; ${ }^{2}$ Institute of Veterinary Pathology, Winterthurerstrasse 268, CH-8057 Zurich, Switzerland
}

\begin{abstract}
Viruses have been proposed as etiologic cofactors in the pathogenesis of HIVrelated neurological disease. To investigate the etiologic potential of Borna disease virus (BDV) in these disorders, two populations were studied: (1) 27 prospectively identified patients with various neurological disorders were evaluated with BDV RT-PCR (CSF, PBMC), and BDV serology, and (2) a separate group of 25 retrospectively studied patients with AIDS dementia complex was evaluated using BDV serology only. A novel, BDV p40 gene RT PCR assay was developed: conserved primers were used in a non-nested amplification, detecting less than 100 BDV RNA copies and all of nine wildtype, confirmed animal BDV infections. BDV seroprevalences were $12.5 \%$ and $8.0 \%$, respectively, which are similar to the general HIV-infected population. None of the prospectively studied patients had detectable BDV RNA in their CSF or PBMC. Our findings do not support the hypothesis that BDV infections are responsible for HIV-related neurological disorders.
\end{abstract}

Keywords: BDV; AIDS dementia complex; human immunodeficiency virus; PCR; serology; CSF

\section{Introduction}

Two lines of evidence suggested that BDV may cause disease in HIV-infected patients. First, reports that BDV seroprevalence is higher among HIVinfected persons than among the general population (Auwanit et al, 1996; Bode et al, 1988) suggest that there may also be a higher prevalence of BDV infection in HIV-infected groups. Second, idiopathic neurologic disorders are frequently found among HIV-infected patients with advanced HIV disease. Other viruses have been proposed as possible cofactors in the etiology of HIV-related neurological disease and, in particular, AIDS dementia complex (ADC) (Lipton and Gendelman, 1995).

The presence of viral antigens, BDV RNA and histopathological changes have been demonstrated in human brain tissues (De La Torre et al, 1996; Haga et al, 1997; Salvatore et al, 1997). Although some reports describe the presence of BDV RNA in PBMCs from psychiatric patients (Bode et al, 1995; Kishi et al, 1995b), others have not detected BDV

Correspondence: Dr R Cone

Received 8 April 1998; revised 27 July 1998; accepted 3 August 1998
RNA in similar groups (Lieb et al, 1997; Richt et al, 1997; Sierra Honigmann et al, 1995).

In order to characterise the possible role of BDV as a viral cofactor in HIV-associated neurological disorders, we analysed cerebrospinal fluid (CSF) and peripheral blood mononuclear cells (PBMC) with a newly developed RT-PCR, and plasma or sera were evaluated with a previously published BDV serologic test (Caplazi et al, 1994). This is the first report to our knowledge that uses RT - PCR to evaluate BDV infections among HIV-infected persons.

\section{Results}

Development of new BDV PCR primers

Novel BDV primers and probes were developed for this study. To identify conserved primer-binding sites, all BDV sequences published in the GenBank and EMBL sequence databases as of November 15, 1996, were identified. The BDV p40 gene was the most often reported BDV sequence, with six independent sequence strings (BDVPT1P40, BDVPT2P40, BDVPT3P40 (Bode et al, 1995), TOGBDVSEQ (Cubitt et al, 1994), BD04608 (Briese 
et al, 1994) and S62821 (Pyper et al, 1993). An alignment of all six available p40-sequences revealed an interrupted consensus sequence in which all six sequence strings had homology (Figure 1).

The consensus sequence was evaluated for suitable primers and probes that had the best sequence conservation, minimum intra- and interstrand duplex formation, minimum false priming sites, and the lowest melting temperature difference between the primers. The resulting BDV PCR primer pair (upper: BD139U, Lower: BD139L) and probe (BD139P) produce a product of 139 base pairs (Figure 1). BD139U and BD139P had no mismatches compared to the consensus sequence. The lower primer, BD139L, contained two mismatches relative to the consensus sequence at positions four and seven from the $5^{\prime}$ end (Figure 1). To avoid potential amplification problems due to these mismatches, BD139L was synthesised with inosine substitutions at positions four and seven because inosine can reportedly hybridise to any of the four normal nucleotides with approximately equal affinity (Cassol et al, 1991).

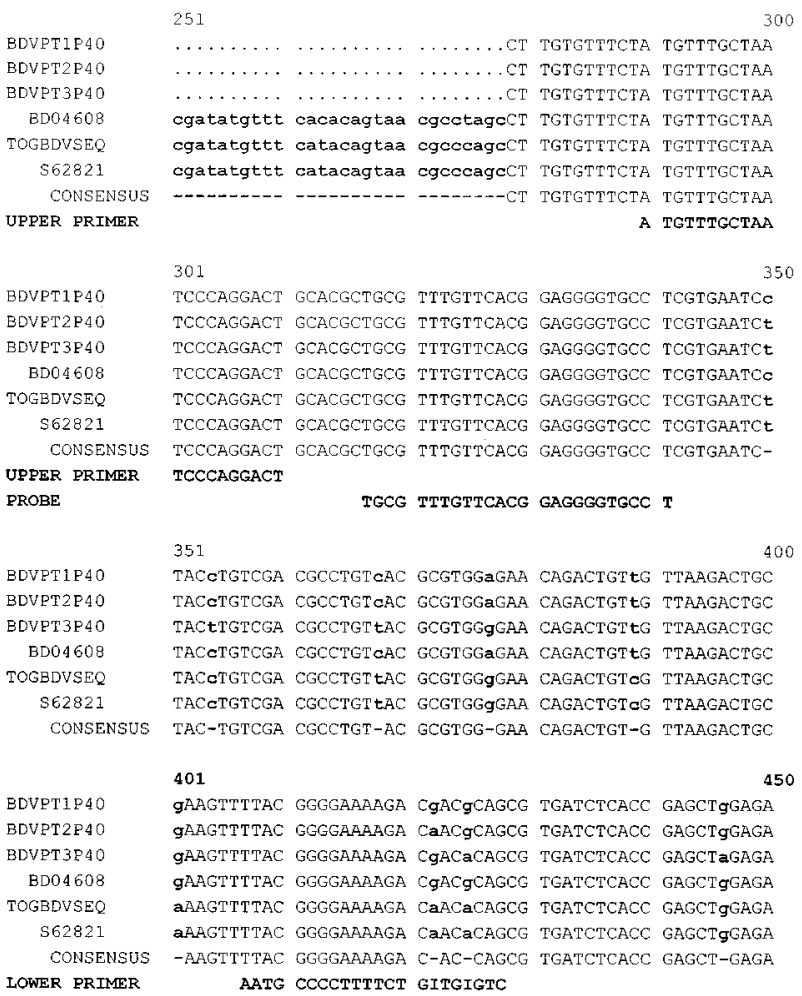

Figure 1 Alignment of six p40 gene sequences and their consensus sequence. Consensus at each position was only accepted when all sequences were identical. Lower case bold indicates absence of consensus at that position for one or more of the six sequences. The BDV139 primers and probe are indicated in bold upper case. The sequence numbering corresponds to the complete genomic sequence BD04608 (Briese et al, 1994).
The PCR reaction was optimised with respect to $\mathrm{MgCl}_{2}$ concentration (1, 1.5, 2 and $3 \mathrm{mM}$ ), glycerol concentration (0,10 and 20\%), TaqStart Antibody (0 or $0.5 \mu \mathrm{l}$ per reaction), annealing temperature (50, $52,54,56,58,60$ and $\left.62^{\circ} \mathrm{C}\right)$, annealing time $(20 \mathrm{~s}$, $20 \mathrm{~s}$ plus $1 \mathrm{~s}$ cycle, $45 \mathrm{~s}$ ) and denaturation temperature $\left(95,94\right.$ and $\left.93^{\circ} \mathrm{C}\right)$. In the RT step, reactions primed with the specific BDV primer (BD139U) produced more PCR product than reactions primed with random hexamers.

The sensitivity of the BD139 RT - PCR assay was tested in three ways. Conservation of the primer sequences was evaluated by testing brain tissues from nine animals with documented BDV infections (classical clinical syndrome and positive brain tissues by immunohistochemistry), including six horses, two sheep and one donkey. All nine cases were positive in the BD139 RT-PCR assay. The lower limit of detection was evaluated first by amplifying dilutions of RNA extracted from BDVpositive, cultured cells. This demonstrated BDV RT - PCR positivity in RNA from 0.1 infected cell equivalents per reaction. The lower limit was further evaluated by amplifying dilutions of in vitro generated, quantitated p40 gene RNA, demonstrating detection of fewer than 100 BDV RNA copies per amplification reaction.

\section{Prospectively studied cohort with various neurological disorders}

Clinical and demographic data from the prospectively studied cohort are summarised in Table 1 . The median age of the 27 subjects (seven women) was 34 years (range, $28-71$ ). The median CD4 count at the time of spinal tap was $60 \mathrm{CD} 4$ cells/ $\mu$ l (range 0 to 440). The median duration of followup was 175 days (range, $4-433$ days).

BDV RNA was not detected in any of the 27 PBMC or CSF specimens from HIV-infected patients with neurological diseases. The average amount of total RNA recovered from 26 of 27 PBMC specimens was $2.44 \mu \mathrm{g}$ per specimen; the RNA content of one specimen could not be assessed for technical reasons. Since many patients in this cohort had lymphopenia secondary to advanced HIV disease, RNA yields varied from $0.12-6.66 \mu \mathrm{g}$ per PBMC specimen. Suitability of the extracted RNA for amplification was confirmed by semiquantitative beta-actin RT-PCR, which was positive in all 26 RNA specimens tested. Since detectable RNA was not expected from $0.14 \mathrm{ml} \mathrm{CSF}$, RNA levels in these specimens were not measured.

RNAs extracted from all 27 PBMC and CSF specimens were tested by BDV RT - PCR in duplicate, and several positive and negative controls were included in every run, assuring consistent performance of the assay. In addition to the PCR data, BDV serologies performed on simultaneously collected sera from 16 of the 27 subjects revealed 2 $(12.5 \%)$ that were positive (titers, $1: 40$ and $1: 80$ ). 
Table 1

\begin{tabular}{|c|c|c|c|c|c|c|}
\hline$\overline{\text { Subject }}$ & $A g e^{a}$ & $\overline{\text { Gender }}$ & Stage $^{b}$ & $C D 4 / \mu l$ & Reason for tap ${ }^{c}$ & Final neurological diagnosis ${ }^{c}$ \\
\hline 1 & 47 & M & C3 & 0 & R/O PML (apraxia, brain atrophy, paralysis) & $\mathrm{ADC}$ \\
\hline 2 & 38 & $\mathrm{~F}$ & C3 & 90 & Confirm ADC & $\mathrm{ADC}$ \\
\hline 3 & 28 & $\mathrm{M}$ & A3 & 110 & R/O Neurosyphilis & None \\
\hline 4 & 34 & $\mathrm{M}$ & C3 & 0 & R/O PML (ataxia, memory loss) & Presumptive PML \\
\hline 5 & 45 & $\mathrm{M}$ & C3 & 60 & Confirm cerebral toxoplasmosis & Cerebral toxoplasmosis \\
\hline 6 & 71 & $\mathrm{M}$ & B3 & 60 & Progressive paralysis & Idiopathic hemorrhagic spinal cord necrosis \\
\hline 7 & 34 & M & C3 & 30 & Polyneuropathy & d4T-associated polyneuropathy \\
\hline 8 & 41 & $\mathrm{M}$ & C3 & 10 & Left hemiparesis & Suspected CNS lymphoma \\
\hline 9 & 32 & $\mathrm{~F}$ & C3 & 80 & R/O PML (hemiparesis) & Presumptive PML \\
\hline 10 & 30 & $\mathrm{~F}$ & C3 & 274 & R/O PML & PML \\
\hline 11 & 34 & $\mathrm{M}$ & C3 & 0 & Confirm ADC (word-finding abnormality) & None \\
\hline 12 & 33 & M & B3 & 0 & $\begin{array}{l}\text { R/O toxoplasmosis, lymphoma (aphasia, } \\
\text { cerebral hyperdensity) }\end{array}$ & Suspected TIA, microangiopathy \\
\hline 13 & 39 & $\mathrm{~F}$ & C3 & 10 & $\mathrm{R} / \mathrm{O}$ cerebral cryptococcosis & Cryptococcal meningitis \\
\hline 14 & 40 & $\mathrm{M}$ & $\mathrm{C} 2$ & 250 & $\mathrm{R} / \mathrm{O}$ residual cerebral borreliosis & Status post borreliosis \\
\hline 15 & 37 & $\mathrm{M}$ & A3 & 200 & Radiculitis & Lumboradicular syndrome \\
\hline 16 & 33 & $\mathrm{M}$ & C3 & 20 & Confirm cerebral toxoplasmosis & Cerebral toxoplasmosis \\
\hline 17 & 31 & $\mathrm{M}$ & B3 & 80 & R/O PML & Presumptive PML \\
\hline 18 & 32 & M & A2 & 440 & $\mathrm{R} / \mathrm{O}$ neurosphyilis & Syphilis ruled out \\
\hline 19 & 28 & $\mathrm{~F}$ & C3 & 30 & Paraparesis & $\mathrm{ADC}$ \\
\hline 20 & 29 & $\mathrm{~F}$ & C3 & 10 & R/O PML & PML \\
\hline 21 & 34 & $\mathrm{M}$ & C3 & 0 & Left hemiparesis & Polyradiculitis, CMV retinitis \\
\hline 22 & 42 & $\mathrm{M}$ & C3 & 70 & Confirm ADC (general brain atrophy) & None \\
\hline 23 & 49 & M & A2 & 318 & Confirm neurosyphilis & Neurosyphilis \\
\hline 24 & 33 & M & C3 & 40 & R/O PML & $\begin{array}{l}\text { Presumptive PML, status post } \\
\text { toxoplasmosis }\end{array}$ \\
\hline 25 & 35 & $\mathrm{~F}$ & C3 & 150 & Confirm cryptococcal meningitis & Cryptococcal meningitis \\
\hline 26 & 36 & $\mathrm{M}$ & B2 & 284 & $\mathrm{R} / \mathrm{O}$ residual neurosyphilis & Status post neurovascular syphilis \\
\hline 27 & 36 & $\mathrm{M}$ & C3 & 10 & Romberg's sign & CMV encephalitis/retinitis \\
\hline
\end{tabular}

${ }^{\mathrm{a}}$ Age in years. ${ }^{\mathrm{b}} \mathrm{CDC}$ stage of HIV infection. ${ }^{\mathrm{c}} \mathrm{R} / \mathrm{O}$, rule out; ADC, AIDS dementia complex; PML, progressive multifocal leukoencephalopathy; TIA, transient ischemic attack.

Retrospectively studied cohort with $A D C$

Sera from 25 retrospectively studied HIV-infected subjects with a diagnosis of AIDS dementia complex (ADC) were evaluated by BDV serology: 2 of 25 $(8.0 \%)$ subjects were antibody positive (both titers, $1: 40)$.

\section{Discussion}

This study suggests that BDV infections do not play an important role in the pathogenesis of neurological illnesses among the two cohorts of HIV-infected subjects reported here. The prospectively studied cohort of 27 HIV-infected subjects with various neurological problems had no detectable BDV RNA in their CSF or PBMCs. The BDV seroprevalence in this group was $12.5 \%(2 / 16)$. The retrospectively studied cohort of $25 \mathrm{HIV}$ infected patients with AIDS dementia complex (ADC) was evaluated with BDV serologies only, resulting in a seroprevalence of $8.0 \%(2 / 25)$. These seroprevalences are similar to those previously reported for the general HIV-infected population (Auwanit et al, 1996; Bode et al, 1988), suggesting no increased seroprevalence among those with neurological disorders.
The use of PBMC specimens for BDV detection was based on other reports that assessed BDV infections in humans (Bode et al, 1995; Kishi et al, 1995b; Lieb et al, 1997; Nakaya et al, 1996; Richt et al, 1997). The topic of BDV RNA in PBMC specimens has stirred controversy. Sauder et al (1996) reported BDV RNA positivity by p24 and/or p40 RT-PCR in 50\% of PBMC specimens from 26 patients with psychiatric disorders. The PCR results were also confirmed in a separate laboratory. Interestingly, most of the BDV RNApositive patients were BDV seronegative. In contrast, Lieb et al (1997) found no BDV RNA in blood from a different group of psychiatric patients attending the same hospital as used by Sauder et al (1996). The negative PCR results from Lieb et al (1997) were also confirmed in two separate laboratories. In view of this ongoing debate, we do not rule out the presence of BDV RNA in brain tissue on the basis of negative PBMC BDV RNA data.

The newly developed BDV RT-PCR assay reported here has theoretical advantages over some existing BDV RT-PCR methods. The single round of amplification used here can provide better quantitation than the nested PCR protocols previously reported (Bode et al, 1995; Kishi et al, 
1995a, b; Sierra Honigmann et al, 1993; Sorg and Metzler, 1995; Zimmermann et al, 1994), while reducing the risk of contamination inherent in nested methods. Although single round PCR can be less sensitive than nested PCR, sensitivity of less than 100 BDV RNA copies was achieved by detecting the PCR products with radioactive probes. Furthermore, the primers were based on conserved BDV sequences, improving the chances of detecting wild-type variants that may differ from characterised strains. Success in this respect was demonstrated by detecting BDV RNA in all of nine BDVinfected animal brain tissues.

Patients meeting our case definition do not typically undergo brain biopsies, so brain tissues from these subjects were not available. Instead, we studied CSF specimens to assess CNS infection. However, the RT-PCR-negative results from CSF specimens in this study must be interpreted with caution. First, we are not aware of evidence that CSF contains BDV RNA in documented infections. Since BDV is cell associated, the failure to detect BDV-RNA in CSF could reflect the inadequacy of this specimen type. Second, we used small volumes of CSF for PCR and did not document RNA recovery from these specimens. The use of BDV RT - PCR in CSF specimens was previously assessed in a cohort of schizophrenic patients in which no viral RNA was detected (Sierra Honigmann et al, 1995). Attempts to culture BDV from CSF of three BDVseropositive patients suggested the presence of BDV, but the results were inconclusive because the cultures failed to propagate virus after passage (Richt et al, 1993).

BDV seroprevalence is reportedly higher in HIVinfected populations than in the general population, raising the possibility that $\mathrm{HIV}$-infected patients are more frequently infected with BDV. Bode et al previously reported that HIV-infected individuals in the US and England have a higher BDV seroprevalence $(7.8 \%)$ than the general population $(2.0 \%)$ (Bode et al, 1988). A study performed on HIV-1-infected subjects in Thailand reported BDV seroprevalences of $8.3 \%$ among prostitutes, $0 \%$ among IV drug users, and $2 \%$ among HIV-negative blood donors (Auwanit et al, 1996). Surprisingly, a subgroup of HIV-infected patients with sexually transmitted diseases had a very high BDV seroprevalence $(38 \%)$. Our study of HIV-infected individuals with neurological disorders revealed an overall BDV seropositivity of $9.8 \%$, which is similar to the seroprevalence in unselected HIV-infected individuals from England and the US. The BDV PCR data reported here are the first, to our knowledge, addressing actual viral replication among HIVinfected patients.

In summary, our RT - PCR and serological data did not confirm the presence of BDV in these cohorts of HIV-infected patients with neurological disorders. Although these negative results do not rule out $\mathrm{BDV}$ infections, they suggest that $\mathrm{BDV}$ infections are not a prominent etiology of neurological disorders in this immunocompromised population.

\section{Materials and methods}

Subjects

Two groups of subjects were studied. In the first group, 27 HIV-infected patients with various neurological disorders were prospectively enrolled between May, 1995 and April, 1996 at the Zurich University Hospital. The enrollment criteria were (1) documented HIV infection and (2) spinal tap for any reason. At the time of spinal tap, at least $1 \mathrm{ml}$ CSF and $16 \mathrm{ml}$ anticoagulated blood (CPT Vacutainer, Becton Dickinson, Meylan, France) were collected. Within $4 \mathrm{~h}$ of collection, aliquots of peripheral blood mononuclear cells (PBMC), plasma and CSF were stored at $-70^{\circ} \mathrm{C}$. Clinical data from each patient were recorded on case report forms, including neuropsychological, cognitive, social, and motor disorders, history of animal contact, primary diagnosis, reason for spinal tap, results of brain imaging and followup information including definitive diagnosis (Table 1). This research on human subjects was approved by the Ethical Committee (Human Subjects Review Board) of the University Hospital.

The second group of 25 patients was retrospectively identified by searching the Swiss HIV Cohort Database (Ledergerber et al, 1994) for patients with (1) AIDS dementia complex (ADC) and (2) stored serum obtained within 1 month of ADC diagnosis. The 25 cases of ADC were diagnosed between November, 1988 and July, 1994. The tested sera were closely matched to the date of ADC diagnosis, with a median difference between diagnosis and serum collection of 1 day.

\section{$B D V R T-P C R$}

Searches of the GenBank and EMBL sequence databases (November 15, 1995) and sequence alignments were performed with GCG-8 software (Wisconsin Package, Version 8 for Silicon Graphics computers, Genetics Computer Group, Madison, WI, USA). Identification of primers and probes in the BDV p40 consensus sequence was performed with Oligo software (OLIGO primer analysis software, Version 5.0 for Windows, National Biosciences, Inc., Annapolis Lane, Plymouth, MN, USA).

BDV RT-PCR was performed as follows. RNA (final volume, $50 \mu \mathrm{l}$ ) was extracted from $5 \times 10^{6}$ patient PBMCs, animal brain tissue, or control cell lines (BDV He/80-infected and -uninfected C6 cells) using the RNeasy Kit (Qiagen AG, Basel, Switzerland) or from $140 \mu \mathrm{l} \mathrm{CSF}$ using the QIAamp HCV Kit (Qiagen) according to the manufacturer's instructions. For PBMC extractions, RNA yields were 
determined by measuring fluorescence with RiboGreen RNA quantitation reagent (Molecular Probes Europe BV, Leiden, The Netherlands) according to the manufacturer's instructions. Before reverse transcription, a mixture containing $5 \mu \mathrm{l}$ RNA $(10 \%$ of total extracted RNA) and $6 \mu \mathrm{l}$ primer BD139U (5'ATG TTT GCT AAT CCC AGG ACT-3') $\left(1.3 \times 10^{12}\right.$ molecules, or 22 pmoles, primer) was denatured at $70^{\circ} \mathrm{C}$ for $10 \mathrm{~min}$. The mixture was then reverse transcribed using the Expand Reverse Transcriptase kit (Boehringer Mannheim AG, Rotkreuz, Switzerland) according to the manufacturer's instructions, except that the incubation proceeded for $10 \mathrm{~min}$ at $30^{\circ} \mathrm{C}$ followed by $42^{\circ} \mathrm{C}$ for an additional $45 \mathrm{~min}$. Amplification reactions $(100 \mu \mathrm{l})$ containing $5 \mu \mathrm{l}$ $(25 \%)$ of the RT reaction and $50 \mu \mathrm{l} 2 \times$ master mix [2.5 U AmpliTaq polymerase, $2 \times$ PCR buffer (both Perkin Elmer AG, Rotkreuz, Switzerland), $400 \mu \mathrm{M}$ each dNTP, and $0.55 \mu \mathrm{g}$ TaqStart antibody (Clonetech Laboratories Inc., Palo Alto, CA, USA), $5 \times 10^{13}$ molecules (83 pmoles) of each primer, BD139U and BD139L (5'-CTG IGT IGT CTT TTC CCC GTA A-3')] were denatured $\left(2 \mathrm{~min}\right.$ at $\left.94^{\circ} \mathrm{C}\right)$, amplified with 35 cycles $\left(30 \mathrm{~s}\right.$ at $94^{\circ} \mathrm{C}, 45 \mathrm{~s}$ at $60^{\circ} \mathrm{C}$ and $30 \mathrm{~s}$ at $\left.72^{\circ} \mathrm{C}\right)$ and extended for $5 \mathrm{~min}$ at $72^{\circ} \mathrm{C}$. Amplified products were detected using ethidium bromide-stained gels and by liquid hybridisation. For hybridisation, $7 \mu \mathrm{l}$ of PCR-product and $18 \mu \mathrm{l}$ hybridisation solution [per hybridisation, $12.5 \mu \mathrm{l}(50 \%)$ deionised formamide (Fluka, Buchs, Switzerland), $10^{6}$ c.p.m. ${ }^{32} \mathrm{P}-$ labelled probe (BD139P: 5'-TGC GTT TGT TCA CGG AGG GGT GCC T-3'), $1 \mu \mathrm{l} 5 \mathrm{M} \mathrm{NaCl}, 0.5 \mu \mathrm{l}$ $5 \mathrm{mM}$ each dNTP (dNTP Set, Pharmacia, Piscataway, NJ, USA) and water to $18 \mu \mathrm{l}$ ] were denatured at $97^{\circ} \mathrm{C}$ for $5 \mathrm{~min}$ and hybridised by linear cooling to $30^{\circ} \mathrm{C}$ over $15 \mathrm{~min}$ in a thermal cycler. Ten $\mu \mathrm{l}$ of hybridised mixture were electrophoresed in agarose gels $(2.25 \%$ NuSieve $/ 0.75 \%$ MP agarose (FMC, Rockland, ME, USA, and Boehringer-Mannheim, respectively). The gels were dried and autoradiographed. Radioactive hybridisation improved the sensitivity of detection by at least two orders of magnitude.

\section{Beta-actin RT-PCR}

Recovery of amplifiable PBMC RNA was documented by semi-quantitative beta-actin RT-PCR. Primers designed in house correspond to beta-actin mRNA exons 3 (35up; 5'-GTCACCAACTGGGACGACATGGAGAA) and 4 (36low; 5'-CATGGCTGGGGTGTTGAAGGTCTCA), resulting in a $171 \mathrm{bp}$ PCR product. Amplifications were performed with the EZ rTth RNA PCR kit (Perkin-Elmer, Foster City, CA, USA) according to the suppliers suggestions. Briefly, $25 \mu \mathrm{l}$ master mix $(0.2 \mathrm{mM}$ dNTP, $1 \times \mathrm{EZ}$ buffer, $1.5 \mathrm{mM} \mathrm{Mn}(\mathrm{OAc})_{2}, 0.5 \mu \mathrm{M}$ each primer and $0.15 \mathrm{U} / \mu \mathrm{l}$ Tth DNA polymerase) and $1 \mu \mathrm{l}$ template RNA were amplified in a T3 thermocycler (Biometra, Göttingen, Germany) as follows: $94^{\circ} \mathrm{C}$ for $45 \mathrm{~s}$, $62^{\circ} \mathrm{C}$ for $20 \mathrm{~min}, 3$ cycles of $95^{\circ} \mathrm{C}$ for $15 \mathrm{~s}, 62^{\circ} \mathrm{C}$ for
$10 \mathrm{~s}$ and $72^{\circ} \mathrm{C}$ for $30 \mathrm{~s}$, then 22 cycles of $90^{\circ} \mathrm{C}$ for $15 \mathrm{~s}, 62^{\circ} \mathrm{C}$ for $10 \mathrm{~s}$ and $72^{\circ} \mathrm{C}$ for $30 \mathrm{~s}$, followed by $72^{\circ} \mathrm{C}$ for $15 \mathrm{~min}$ and cooling to $4^{\circ} \mathrm{C}$. PCR products were electrophoresed in agarose gels and visualised with SYBR Gold nucleic acid stain (Molecular probes, Eugene, Oregon, USA). Digital images of the gels were created by scanning Polaroid photographs, and band intensities were determined using image analysis software (Intelligent Quantifier, Biolmage, Ann Arbor, MI, USA). Copy numbers were calculated from band intensities by comparison to actin RT-PCR products from PBMC RNA standards.

\section{$B D V$ serology and immunohistochemistry}

BDV serologies were performed as previously described (Caplazi et al, 1994). Briefly, BDV strain He/80-infected MDCK or C6 cells were fixed in acetone, incubated with threefold serum dilutions $\left(37^{\circ} \mathrm{C}, 1 \mathrm{~h}\right.$, washed three times, incubated with antihuman FITC conjugate $\left(37^{\circ} \mathrm{C}, 1 \mathrm{~h}\right)$, washed three times, counterstained with Evans blue, washed and mounted. Serum dilutions were scored as positive or negative based on the intensity of intranuclear signal under fluorescent microscopy.

BDV infection in the brain tissue samples used as positive control material for PCR was established by immunohistochemistry as described (Caplazi et al, 1994).

Paraffin sections of brain tissues from nine animals suffering from clinically manifest Borna encephalitis were deparaffinised and treated with $0.1 \%(\mathrm{w} / \mathrm{v})$ protease (type XXVII, Sigma, Buchs, Switzerland). The monoclonal anti-BDV antibody $38 / 17$ C1, recognising BDV p38, was used in a peroxidase streptavidin-biotin method (LSAB, DAKO, Glostrup, Denmark) with AEC as a chromogen. Specific signals were detected microscopically. A positive tissue sample and mock reactions without primary antibody were included in each assay to monitor the performance of the protocol.

\section{Acknowledgements}

This work was supported in part by a grant from the EMDO Stiftung Zurich. We gratefully acknowledge Ines Zangger and Marianne Kuster for providing CSF specimens and Bruno Ledergerber for assistance with the Swiss HIV Cohort Database. Clinical information and sera from the retrospectively identified patients were available from the Swiss HIV Cohort Study Group. The monoclonal antibody 38/17 C1 was a kind gift from Lothar Stitz, Bundesforschungsanstalt fuer Viruskrankheiten, Tuebingen, Germany. 


\section{References}

Auwanit W, Ayuthaya PI, Nakaya T, Fujiwara S, Kurata $\mathrm{T}$, Yamanishi K, Ikuta K (1996). Usually high seroprevalence of Borna disease virus in clade $\mathrm{E}$ human immunodeficiency virus type 1-infected patients with sexually transmitted diseases in Thailand. Clin Diagn Lab Immunol 3: 590-593.

Bode L, Riegel S, Ludwig H, Amsterdam JD, Lange W, Koprowski H (1988). Borna disease virus-specific antibodies in patients with HIV infection and with mental disorders [letter]. Lancet 2: 689.

Bode L, Zimmermann W, Ferszt R, Steinbach F, Ludwig $H$ (1995). Borna disease virus genome transcribed and expressed in psychiatric patients [see comments]. Nat Med 1: 232-236.

Briese T, Schneemann A, Lewis AJ, Park YS, Kim S, Ludwig H, Lipkin WI (1994). Genomic organization of Borna disease virus. Proc Natl Acad Sci USA 91: $4362-4366$.

Caplazi P, Waldvogel A, Stitz L, Braun U, Ehrensperger F (1994). Borna disease in naturally infected cattle. $J$ Comp Pathol 111: 65-72.

Cassol S, Salas T, Lapointe N, Arella M, Rudnik J, O’Shaughnessy M (1991). Improved detection of HIV-1 envelope sequences using optimized PCR and inosinesubstituted primers. Mol Cell Probes 5: 157-160.

Cubitt B, Oldstone C, de la Torre JC (1994). Sequence and genome organization of Borna disease virus. $J$ Virol 68, $1382-1396$.

De La Torre JC, Gonzalez Dunia D, Cubitt B, Mallory M, Mueller Lantzsch N, Grasser FA, Hansen LA, Masliah E (1996). Detection of borna disease virus antigen and RNA in human autopsy brain samples from neuropsychiatric patients. Virology 223: 272-282.

Haga S, Yoshimura M, Motoi Y, Arima K, Aizawa T, Ikuta K, Tashiro M, Ikeda K (1997). Detection of Borna disease virus genome in normal human brain tissue. Brain Res 770: $307-309$.

Kishi M, Nakaya T, Nakamura Y, Kakinuma M, Takahashi TA, Sekiguchi S, Uchikawa M, Tadokoro K, Ikeda K, Ikuta K (1995a). Prevalence of Borna disease virus RNA in peripheral blood mononuclear cells from blood donors. Med Microbiol Immunol Berl 184: $135-138$.

Kishi M, Nakaya T, Nakamura Y, Zhong Q, Ikeda K, Senjo M, Kakinuma M, Kato S, Ikuta K (1995b). Demonstration of human Borna disease virus RNA in human peripheral blood mononuclear cells. FEBS Lett 364: $293-297$.

Ledergerber B, von Overbeck J, Egger M, Lüthy R, Swiss HIV Cohort Study (1994). The Swiss HIV Cohort Study: rationale, organization and selected baseline characteristics. Soz Praventivmed 39: 387-394.

Lieb K, Hallensleben W, Czygan M, Stitz L, Staeheli P (1997). No Borna disease virus-specific RNA detected in blood from psychiatric patients in different regions of Germany. The Bornavirus Study Group [letter]. Lancet 350: 1002.
Lipton SA, Gendelman HE (1995). Seminars in medicine of the Beth Israel Hospital, Boston. Dementia associated with the acquired immunodeficiency syndrome. $N$ Engl J Med 332: 934-940.

Nakaya T, Takahashi H, Nakamura Y, Asahi S, Tobiume M, Kuratsune H, Kitani T, Yamanishi K, Ikuta K (1996). Demonstration of Borna disease virus RNA in peripheral blood mononuclear cells derived from Japanese patients with chronic fatigue syndrome. FEBS Lett 378: $145-149$.

Pyper JM, Richt JA, Brown L, Rott R, Narayan O, Clements JE (1993). Genomic organization of the structural proteins of borna disease virus revealed by a cDNA clone encoding the $38 \mathrm{kDa}$ protein. Virology 195: $229-238$.

Richt JA, Alexander RC, Herzog S, Hooper DC, Kean R, Spitsin S, Bechter K, Schuttler R, Feldmann H, Heiske A, Fu ZF, Dietzschold B, Rott R, Koprowski H (1997). Failure to detect Borna disease virus infection in peripheral blood leukocytes from humans with psychiatric disorders. J Neurovirol 3: 174-178.

Richt JA, Herzog S, Pyper J, Clements JE, Narayan O, Bechter K, Rott R (1993). Borna disease virus: nature of the etiologic agent and significance of infection in man. Arch Virol Suppl 7: 101-109.

Salvatore M, Morzunov S, Schwemmle M, Lipkin WI (1997). Borna disease virus in brains of North American and European people with schizophrenia and bipolar disorder. Bornavirus Study Group. Lancet 349: $1813-1814$.

Sauder C, Muller A, Cubitt B, Mayer J, Steinmetz J, Trabert W, Ziegler B, Wanke K, Mueller Lantzsch N, de la Torre JC, Grasser FA (1996). Detection of Borna disease virus (BDV) antibodies and BDV RNA in psychiatric patients: evidence for high sequence conservation of human blood-derived BDV RNA. J Virol 70, 7713-7724.

Sierra Honigmann AM, Carbone KM, Yolken RH (1995). Polymerase chain reaction (PCR) search for viral nucleic acid sequences in schizophrenia. $\mathrm{Br} J$ Psychiatry 166: 55-60.

Sierra Honigmann AM, Rubin SA, Estafanous MG, Yolken RH, Carbone KM (1993). Borna disease virus in peripheral blood mononuclear and bone marrow cells of neonatally and chronically infected rats. $J$ Neuroimmunol 45: $31-36$.

Sorg I, Metzler A (1995). Detection of Borna disease virus RNA in formalin-fixed, paraffin-embedded brain tissues by nested PCR. J Clin Microbiol 33: 821-823.

Zimmermann W, Durrwald R, Ludwig H (1994). Detection of Borna disease virus RNA in naturally infected animals by a nested polymerase chain reaction. J Virol Methods 46: $133-143$. 